\title{
The Economic Assessment of the Solution to the Multi-Criteria Problem for Determining Heavy Vehicles Usage Efficiency
}

\author{
https://doi.org/10.3991/ijoe.v17i13.27403 \\ P. Smirnov ${ }^{1(凶)}$, B. Subbotin ${ }^{2}$, V. Klimenko ${ }^{3}$ \\ ${ }^{1}$ Vologda State University, Vologda, Russia \\ ${ }^{2}$ Moscow Automobile and Highway State Technical University, Moscow, Russia \\ ${ }^{3}$ Tomsk State University, Tomsk, Russia \\ smirnovpi@vogu35.ru
}

\begin{abstract}
The article discusses approaches to assessing the effectiveness of the use of heavy vehicles on the example of equipment for the transportation of bulk cargo. The modernization of the existing methods for assessing the effectiveness of its application and the choice of specific operating conditions in the presence of uncertainties and existing restrictions in the environment is proposed, a methodological approach to solving this problem based on the classical theory of linear programming is proposed. As a result, within the framework of the indicated practical problem, the range of optimal solutions for the value of the load-carrying capacity utilization factor has been determined. The modernization of the existing methods for assessing vehicles based on determining the efficiency of their operation, thus, can be recommended for use by the engineering and technical personnel of motor transport enterprises.
\end{abstract}

Keywords - heavy-duty vehicles, load-carrying capacity utilization factor, operating costs, competitiveness assessment

\section{$1 \quad$ Introduction}

In nowadays the issues of optimizing the costs of enterprises of all forms of ownership and types of economic activity have been and continue to be a priority. This is especially true for organizations in the construction and mining industries, because the constant rise in prices for building materials, metals, fuels and lubricants and spare parts puts many transport enterprises or divisions on the brink of profitability of transportation. Intense competition in the market for organizing the transportation of goods both from new specialized firms - market participants, and from the point of view of the implementation of new mechanisms for organizing business - long-term lease of transport, outsourcing and short-term lease, makes the owners look for more and more new ways to optimize economic activities. It is obvious that the issues of choosing a truck and assessing at the selection stage are the way and foundation for solving such a problem, since they largely determine the values of future operating costs at all stages of the life cycle. At the same time, the problem posed, on the one hand, is sufficiently 
researched and solved [1-3], on the other hand, the existing uncertainty in terms of both the current operating environment conditions and possible changes in the current legislation in the field of heavy-duty transport and fiscal restrictions operation, raises many questions about its solution in the modern world.

The article considers the methodology that connects the existing scientific and methodological approaches to the assessment of trucks with the criterion for assessing the effectiveness of their use introduced by the authors - the dependence of productivity on the value of the payload utilization factor (PUF) in the conditions of existing restrictions on public roads operation.

\section{$2 \quad$ Materials and methods}

The existing methods for assessing the efficiency of using vehicles, as a rule, are reduced to a static assessment of the main technical and economic indicators and relatively simple methods of converting these single indicators into an integrated complex assessment. The disadvantage of these approaches lies in linking the solution of the problem of choosing rolling stock to the assessment of equipment at the time of delivery without taking into account the inevitable change in its characteristics and performance indicators during operation and the absence of an assessment of the efficiency of its use. In the work devoted to the issue of assessing the competitiveness of passenger vehicles [4], based on the elaboration of methods for assessing vehicles [5-8], developed a differential method for multi-criteria assessment of vehicles, applicable for use in the current uncertainty of environmental conditions.

\section{Experimental}

From the choosing a truck for commercial use in an organization point of view of, it is necessary to assess the compliance of its main technical characteristics with the requirements put forward [9-11]. Next, it is necessary to calculate the ratio of the "beneficial effect from operation" to the costs of achieving it over the entire life cycle of the truck's operation within the framework of the economic activity of a particular operator [12-14]. Thus, using an integral assessment of the vehicle usage efficiency, it is the above condition that determines the assessment of the level of competitiveness of the vehicles under study (1):

$$
\mathrm{P} \Sigma / 3 \Sigma \rightarrow \max
$$

Vehicle usage efficiency, where P $\Sigma$ is the beneficial effect of operating throughout the entire life cycle at the enterprise and $3 \Sigma$ is the total cost of achieving a useful effect throughout the entire life cycle shows that the most preferable will be the vehicle where this indicator will be greatest.

Also, this ratio can be designated as an integral indicator of product quality in terms of technical and economic indicators - $\kappa_{\mathrm{TOP}}$ :

$$
\kappa \mathrm{TOP}=\mathrm{P} \Sigma / 3 \Sigma
$$


The value of the beneficial effect from operation in terms of transportation of bulk cargo can be determined knowing the performance of trucks (3):

$$
W=\frac{T_{N} \cdot \beta \cdot V_{T} \cdot l_{r l} \cdot q \cdot \gamma_{d}}{l_{r l}+t_{l-u} \cdot \beta \cdot V_{m}},
$$

where $T_{N}$ is the time in the outfit, $h ; \beta$ is the utilization factor of the mileage; $V_{T}$ is average technical speed, $\mathrm{km} / \mathrm{h} ; l_{\mathrm{rl}}$ is the length of the ride with the load, $\mathrm{km}$; $\mathrm{t}_{\mathrm{l}-\mathrm{u}}$ is idle time for loading and unloading, $\mathrm{h}$.

Thus, the multicriteria optimization problem when choosing a rolling stock model from the point of view of assessing the efficiency of its use is reduced to determining the optimal solution from the condition that the selected model meets the following criteria:

1. The minimum unit operating costs, taking into account the period of the planned use at the enterprise;

2. Maximum performance during the planned period of operation.

At the same time, the limitation is the need to minimize potential harm to the coverage of the road network, taking into account current and future legislative or other regulatory restrictions. To solve this problem, it is possible to use the linear programming method considering three efficiency criteria (4) and constraints (5):

$$
\begin{gathered}
K_{1}=a_{11} x_{1}+a_{21} x_{2}+a_{31} x_{3} \rightarrow \max , \\
K_{2}=a_{12} x_{1}+a_{22} x_{2}+a_{32} x_{3} \rightarrow \min , \\
K_{3}=a_{13} x_{1}+a_{23} x_{2}+a_{33} x_{4} \rightarrow \min , \\
x_{1}+x_{2}+x_{3}=N, \\
x_{i}=\left\{\begin{array}{l}
N, i=j \\
O, i \neq j
\end{array}\right.
\end{gathered}
$$

\section{$4 \quad$ Results and discussion}

For the final assessment of the economic efficiency of the proposed methodology for the multicriteria assessment of the indicators of the use of the work of trucks, we will consider the system of equations for the change in specific indicators depending on the change in the value of the PUF.

$$
\left\{\begin{aligned}
p_{t r} f\left(\gamma_{\mathrm{c}}\right) & \rightarrow \max \\
s_{t r} f\left(\gamma_{\mathrm{c}}\right) & \rightarrow \min \\
u_{t r} f\left(\gamma_{\mathrm{c}}\right) & \rightarrow \min
\end{aligned}\right.
$$

where $p_{t r} f\left(\gamma_{\mathrm{c}}\right)$ is the profit function from vehicle transportation, $s_{t r} f\left(\gamma_{\mathrm{c}}\right)$ is the function of unit costs per unit of vehicle mileage, and $u_{t r} f\left(\gamma_{\mathrm{c}}\right)$ is the function of the realized damage to the road surface during the transportation process. On the basis of 
the conducted statistical study, data were obtained on the quantities included in the indicated equations, and the final system is represented as follows (7):

$$
\left\{\begin{array}{c}
y=448,5 x^{2}-737,1 x+327,6 \\
y=50 x^{2}-125 x+116 \\
y=87,5 x^{2}-82,5 x+66
\end{array} .\right.
$$

Let us solve the system of equations by the sequential-graphoanalytical method (Figure 1) (7).

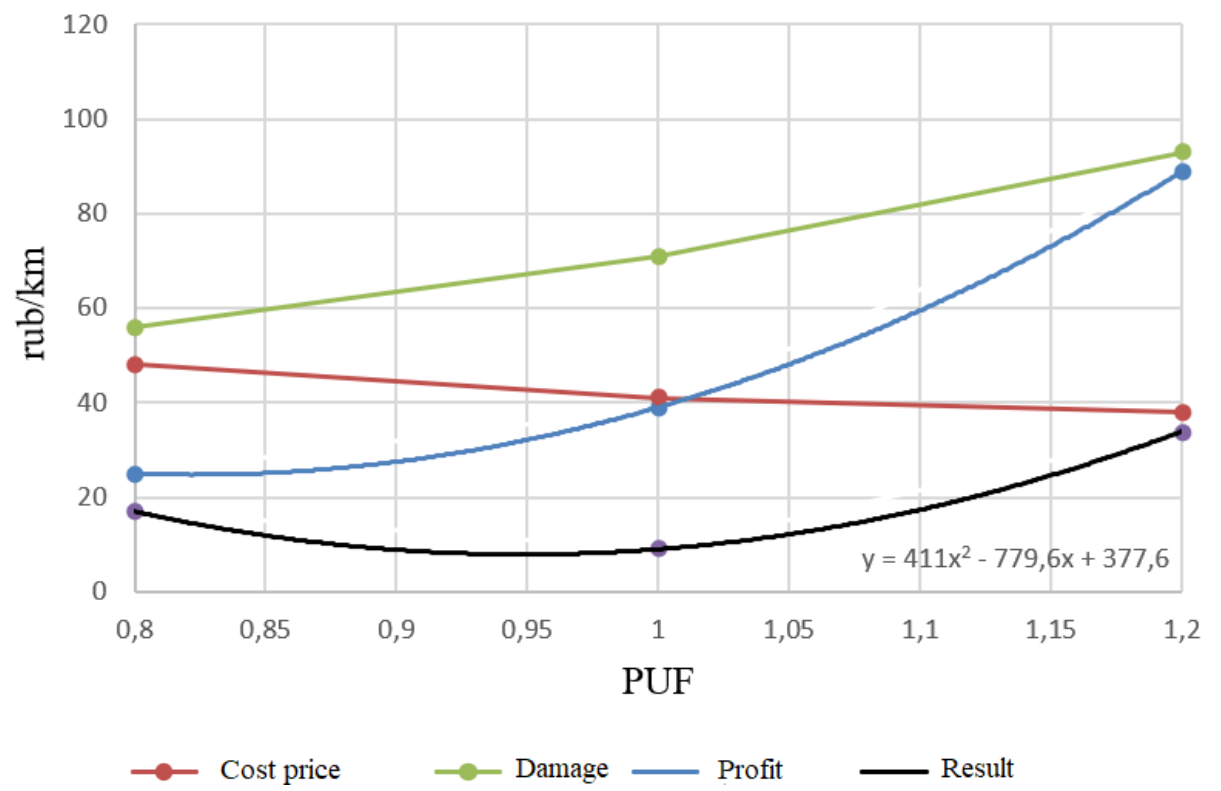

Fig. 1. Graphs of changes in specific economic indicators depending on the change in CIG

To find the optimal value of the PUF, ensuring the minimum total costs in the system under consideration, it is necessary to determine the resulting function $r\left(\gamma_{-} c\right)$ by finding its extremum (Figure 1):

$$
\begin{gathered}
r\left(\gamma_{\mathrm{c}}\right)=411 \gamma_{\mathrm{c}}^{2}-779,6 \gamma_{\mathrm{c}}+377,6 . \\
\gamma_{\mathrm{c}}=0,93
\end{gathered}
$$

\section{Conclusion}

Thus, the modernization of the existing scientific and methodological approach-es to assessing the trucks usage efficiency, in particular when transporting bulk cargo, was carried out by including the PUF criterion in the assessment methodology and establishing the existing PUF links with the previously used criteria for minimizing the unit 
cost operating vehicles throughout the entire life cycle and maximizing vehicle performance. As a limiting criterion, the task of minimizing potential damage to the coverage of the road network was played. As part of the approbation of the method-ology for solving the posed multicriteria optimization problem, the calculation of the economic assessment of the range of optimal values of the PUF for the conditions of a particular operator was performed. At the same time, values from 0.9 to 0.93 were obtained.

\section{References}

[1] Karelina, M. Y., Benevolenskiy, S. B., Terentyev, A. V., Arifullin, I. V., and Karelina, E. A. Application of Methods for Obtaining Pareto Set for Increasing Effectiveness of Managing Decisions Under Conditions of Multi-criteriality. In Proceeding of the International Science and Technology Conference" FarEastCon 2019", 2020, Springer, Singapore, pp. 883890. https://doi.org/10.1007/978-981-15-2244-4 84

[2] Terentyev, A. V., Karelina, M. Y., Cherepnina, T. Y., Linnik, D. A., and Demin, V. A. Digital object-oriented control models in automobile-road complex systems. In IOP Conference Series: Materials Science and Engineering, April 2020, 832: pp. 012058. https://doi.org/10.1088/1757-899x/832/1/012058

[3] Kapustin, A., and Rakov, V. (2017). Methodology to evaluate the impact of hybrid cars engine type on their economic efficiency and environmental safety. Transportation Research Procedia, 20: 247-253. https://doi.org/10.1016/j.trpro.2017.01.057

[4] Terentyev, A. V., Karelina, M. Y., Pavlovskaya, A. A., Arifullin, I. V., and Karelina, E. A. Methodological approach to digitalization of management processes in automobile and road complex. In IOP Conference Series: Materials Science and Engineering, April 2020, IOP Publishing, p. 012069. https://doi.org/10.1088/1757-899x/832/1/012069

[5] Terentyev A V. (2018). Scientific and methodological approach to multi-criteria assessment of the service life of a car Moscow.

[6] Ulyanov V N , Markosyan L. A. (2015). Prospects of lean production development at Russian industrial enterprises. Management systems, 4: 29.

[7] Suslov, I.E. (2013). Metrological support for forecasting the technical condition of motor vehicles/I.E. Suslov, A.G. Sergeev, A.K. Suschev//Motor transport enterprise: journal. - M: NPP "Trans-Navigation," Ministry of Transport of Russia, 10: 46-49.

[8] Karelina, M. Yu. (2018). Analytical determination of weight coefficients in the multi-criteria assessment of the effectiveness of motor vehicles/ M. Yu. Karelina, I. V. Arifullin, A.V. Terentyev/ / Vestnik MADI, 52: 3-9.

[9] Pikalev, O. N. (2014). Evaluation of the competitiveness of buses for urban and intercity transportation: monograph/ O. N. Pikalev. - Vologda: VSU, 119.

[10] Smirnov P. I. (2018). On the issue of choosing the optimal model of rolling stock based on forecasting the values of operating costs . "AGZK + AT", 17:416-419.

[11] Smirnov, P. I.(2020). The method of choosing passenger cars based on the assessment of operating costs: dis. ... Candidate of Technical Sciences: 194.

[12] Terentyev, A.V.(2018). Scientific and methodological approach to the multi-criteria assessment of the car's service life: dis. ... doct. technical Sciences: 289.

[13] Fashiev, H. A. (2004). Evaluation of the economic efficiency of operation and produc-tion of trucks [Text]/ H. A. Fashiev, A.V. Krakhmaleva// Autostandart, 26-30.

[14] Memon, M. A., Hassan, Z., Dahri, K., Shaikh, A., \& Nizamani, M. A. (2019). Aspect Oriented UML to ECORE Model Transformation. The ISC International Journal of Information Security, 11: 97-103. 


\section{$7 \quad$ Authors}

P. Smirnov is with Vologda State University, Vologda, Russia.

B. Subbotin is with Moscow Automobile and Highway State Technical University, Moscow, Russia (email: bsubbotin@mail.ru).

V. Klimenko is with Tomsk State University, Tomsk, Russia (email: klimenko@siberia.design).

Article submitted 2021-10-07. Resubmitted 2021-11-11. Final acceptance 2021-11-13. Final version published as submitted by the authors. 